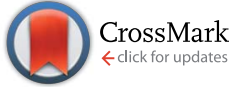

Cite this: RSC AdV., 2017, 7, 12931

Received 28th November 2016 Accepted 5th February 2017

DOI: 10.1039/c6ra27423d

rsc.li/rsc-advances

\section{Controlled synthesis of perovskite lanthanum ferrite nanotubes with excellent electrochemical properties}

\begin{abstract}
Zijiong Li, ${ }^{*}$ Weiyang Zhang, Chaosheng Yuan and Yuling Su
In this work, we have fabricated a series of perovskite-type oxide $\mathrm{LaFeO}_{3}$ samples using a simple sol-gel method and further calcination treatment. We investigated the morphologies, structures and electrochemical performances of the fabricated samples in detail by controlling the calcination temperature and time. The morphology characterization indicates that when the calcination temperature and time are $700{ }^{\circ} \mathrm{C}$ and $3 \mathrm{~h}$, respectively, $\mathrm{LaFeO}_{3}$ presents as a large number of nanotubes with a diameter of $25 \mathrm{~nm}$. Electrochemical performance testing indicates that the tubular $\mathrm{LaFeO}_{3}$ shows excellent electrochemical performance. When $2 \mathrm{M} \mathrm{KOH}$ is used as the electrolyte, the $\mathrm{LaFeO}_{3}$ nanotubes exhibit a high specific capacitance of $313.21 \mathrm{~F} \mathrm{~g}^{-1}$ at a current density of $0.8 \mathrm{~A} \mathrm{~g}^{-1}$. In addition, the electrode maintains $86.1 \%$ of the initial specific capacitance after 5000 cycles at a scan rate of $100 \mathrm{mV}$ $\mathrm{s}^{-1}$, indicating good long-cycle stability. These results indicate that $\mathrm{LaFeO}_{3}$ nanotubes are a novel pseudocapacitance electrode material for application in energy storage devices.
\end{abstract}

\section{Introduction}

Facing with the problems of energy shortage, energy storage and conversion, and environmental pollution, the need to develop sustainable, environmentally friendly and efficient energy storage devices has become a priority. ${ }^{1-3}$ Supercapacitors, a new type of energy storage device with the potential to ensure economic and environmental protection with characteristics of both traditional capacitors and batteries, have broad and important applications in portable electronics, new energy, and other high-tech fields on account of their particular attributes, which include large capacity, high power density, long cycle life, high charge and discharge efficiency, freedom from maintenance, and economic and environmental protection; consequently, they have become a hot research topic in the field of 'new energy' worldwide. ${ }^{4-9}$ As an important part of a pseudocapacitor, the pseudocapacitance electrode material has been a key research topic because of its large specific capacity and high energy density. ${ }^{10-15}$

Transition metal oxides are an important type of pseudocapacitance electrode material and have been studied extensively in recent years because of their high capacitance, excellent redox properties and good electrical conductivity. ${ }^{16,17}$ Lu et al. prepared a novel ternary ordered electrode consisting of a $\mathrm{Co}_{3} \mathrm{O}_{4}$ nanosheet, $\mathrm{Ni}-\mathrm{Co}-\mathrm{O}$ nanorod and nickel foam array in a bottom-up manner; they obtained an excellent electrochemical performance of $2098 \mathrm{~F} \mathrm{~g}^{-1}$ at $5 \mathrm{~mA} \mathrm{~cm}{ }^{-2}$ and $72 \%$ of

School of Physics \& Electronic Engineering, Zhengzhou University of Light Industry, Zhengzhou, 450002, PR China. E-mail: zijiongli@zzuli.edu.cn the specific capacitance was retained after 1000 chargedischarge cycles. ${ }^{18}$ Zhang et al. synthesized an $\mathrm{Fe}_{2} \mathrm{O}_{3}-\mathrm{Ni}(\mathrm{OH})_{2} /$ graphene nanocomposite using a simple one-step hydrothermal method; the nanocomposite demonstrated outstanding electrochemical properties, including a specific capacitance of $857 \mathrm{~F} \mathrm{~g}^{-1}$ and excellent cycling stability $(100 \%$ retention after 5000 cycles).$^{19}$ Perovskite-type oxides have attracted great interest as energy conversion materials for hybrid solar cells and metal-air batteries because of their unique structures and physical and chemical properties. ${ }^{20,21}$ Having the common formula $\mathrm{ABO}_{3}$, where A is a lanthanide or alkali earth element and B is a transition metal, they are an important type of functional nanomaterial, owing to a stable crystal structure, good thermal stability and inherent property of containing oxygen vacancies. In addition, their electrochemical properties have been studied in the electrodes of supercapacitors. ${ }^{22-25}$ However, it is not sufficient only to study the properties of $\mathrm{LaBO}_{3}$ electrode materials in supercapacitors. ${ }^{20,26}$ Perovskite-type oxides $\left(\mathrm{LaBO}_{3}\right)$ merit future study as potential candidate materials for the next generation of supercapacitors and other electrochemical energy storage devices. Esaka $\mathrm{T}$ et al. ${ }^{27}$ showed that the storage of electrochemical energy in perovskite oxides is mainly due to the valence change of B sites caused by hydrogen absorbed in the form of protons. Moreover, Fe is a promising electrode material, as it has many valence states, good electrochemical activity, and high discharge capacity.

In this paper, we prepare perovskite-type oxides $\left(\mathrm{LaFeO}_{3}\right)$ using a simple sol-gel method and further calcination treatment. The analysis results show that the calcination temperature and time have a great impact on the structure, morphology and electrochemical performance of $\mathrm{LaFeO}_{3}$. We obtain a high 
yield of perovskite $\mathrm{LaFeO}_{3}$ nanotubes when the calcination temperature and time are $700{ }^{\circ} \mathrm{C}$ and $3 \mathrm{~h}$, respectively. Furthermore, the perovskite $\mathrm{LaFeO}_{3}$ nanotubes obtained under these calcination conditions have the best specific capacitance of $313.21 \mathrm{~F} \mathrm{~g}^{-1}$ at a current density of $0.8 \mathrm{~A} \mathrm{~g}^{-1}$ and retain $86.1 \%$ of their original capacitance after 5000 charge-discharge cycles at a scan rate of $100 \mathrm{mV} \mathrm{s}^{-1}$. This excellent electrochemical performance is mainly due to the large specific surface area and small resistance attributed to their special structure and morphology. These results indicate that the perovskite $\mathrm{LaFeO}_{3}$ nanotubes show potential as pseudocapacitance electrode materials and are worthy of further investigation.

\section{Experimental section}

\subsection{Material preparation}

Lanthanum nitrate hexahydrate $\left(\mathrm{La}\left(\mathrm{NO}_{3}\right)_{3} \cdot 6 \mathrm{H}_{2} \mathrm{O}\right)$, iron(III) nitrate nonahydrate $\left(\mathrm{Fe}\left(\mathrm{NO}_{3}\right)_{3} \cdot 9 \mathrm{H}_{2} \mathrm{O}\right)$ and polyvinylpyrrolidone (K-30; analytical grade) were purchased from Aladdin-China. $\mathrm{N}, \mathrm{N}$ Dimethylformamide ( $\geq 99.5 \%$; analytical grade) was purchased from Tianjin Kermel Chemical Reagent Co., Ltd.

Preparation of perovskite $\mathrm{LaFeO}_{3}$. In a typical synthesis of perovskite-type $\mathrm{LaFeO}_{3}, 0.866 \mathrm{~g}$ of lanthanum nitrate hexahydrate and $0.808 \mathrm{~g}$ of iron(III) nitrate nonahydrate were dissolved in 50 $\mathrm{mL}$ of $\mathrm{N}, \mathrm{N}$-dimethylformamide and magnetically stirred for $1 \mathrm{~h}$ at a low speed. Next, $0.9 \mathrm{~g}$ of polyvinylpyrrolidone (K-30) was added to the mixture and magnetically stirred continuously to form a homogeneous mixture. The mixed solution was then stirred rapidly and heated to boiling. When the solution had been evaporated to a volume of $1 / 3$ of the original solution, the heating temperature was reduced, and the stirring was continued until a gel was formed. The gel obtained was transferred to a quartz boat and placed in a cold tube furnace, where the temperature was ramped up to $700{ }^{\circ} \mathrm{C}$ at a rate of $5{ }^{\circ} \mathrm{C}$ per minute in air, at which point the gel was heated for $2 \mathrm{~h}$ at $700{ }^{\circ} \mathrm{C}$. The calcination temperature and time (e.g., $700{ }^{\circ} \mathrm{C}$ for $3 \mathrm{~h}, 700{ }^{\circ} \mathrm{C}$ for $4 \mathrm{~h}, 600{ }^{\circ} \mathrm{C}$ for $3 \mathrm{~h}$, or $800{ }^{\circ} \mathrm{C}$ for $3 \mathrm{~h}$ ) were then adjusted to obtain a series of perovskite-structure $\mathrm{LaFeO}_{3}$ samples.

\subsection{Characterization}

The nanostructures and crystal phases of the prepared samples were characterized by X-ray diffraction (XRD; Bruker D8 Advance diffractometer) using $\mathrm{Cu} \mathrm{K} \alpha$ radiation $(\lambda=1.5418 \AA)$ operated at 50 $\mathrm{kV}$ with a scan rate of $0.2^{\circ} \mathrm{s}^{-1}$. The morphologies and sizes of the resulting nanotubes were characterized by field-emission scanning electron microscopy (FESEM; Quanta 250 FEG). Nitrogen adsorption-desorption isotherms were obtained at $77 \mathrm{~K}$ using a micromeritics ASAP 2020 analyzer. Before adsorption, the samples were degassed at $150{ }^{\circ} \mathrm{C}$ under a vacuum of $10^{-4}$ Torr for $6 \mathrm{~h}$. The Brunauer-Emmett-Teller (BET) specific surface area $\left(S_{\mathrm{BET}}\right)$ and the pore size distributions were evaluated using a multipoint BET method and the Barret-Joymer-Halender method, respectively. X-ray photoelectron spectroscopy (XPS) was performed on a Thermo Scientific ESCALAB $250 \mathrm{Xi}$ using $\mathrm{Al} \mathrm{K} \alpha$ radiation (USA).

\subsection{Electrochemical measurements}

The electrochemical performances of the prepared samples were measured on a RST electrochemical workstation (Zhengzhou Shiruisi Technology Co., Ltd). The working electrodes were fabricated by mixing together the prepared materials, conductive carbon black (BP 2000, CABOT, USA), and polytetrafluoroethylene binder in a mass ratio of $8: 1: 1$. A small amount of isopropyl alcohol was added into the mixture to produce a homogeneous paste. The soft paste mixture produced was coated onto $\mathrm{Ni}$ foam and pressed together ( $\sim 0.1 \mathrm{~mm}$ thick). Surplus material was then removed from the electrode so formed. Finally, the electrode was dried in a vacuum oven at $80{ }^{\circ} \mathrm{C}$ for $10 \mathrm{~h}$. After weighing and calculating, the active material on nickel foam was found to be about $2.4 \mathrm{mg}$.

Electrochemical measurements [cyclic voltammetry (CV), galvanostatic charge/discharge (GCD) and electrochemical impedance spectroscopy (EIS)] were carried out in a conventional three-electrode system with $2 \mathrm{M} \mathrm{KOH}$ aqueous solution as the electrolyte. The prepared electrode served as the working electrode, a platinum foil electrode was used as the counter electrode, and $\mathrm{Ag} / \mathrm{AgCl}$ was used as the reference electrode. EIS measurements were carried out in the frequency range from 100 $\mathrm{kHz}$ to $0.01 \mathrm{~Hz}$ with an alternating current amplitude of $5 \mathrm{mV}$. Before electrochemical testing, the working electrode was soaked for $6 \mathrm{~h}$ in $2 \mathrm{M} \mathrm{KOH}$ aqueous solution to create better contact between the active electrode material and the electrolyte.

The specific capacitance $(S c)$ of each electrode was calculated from the following equation:

$$
S c=\frac{I \Delta t}{\Delta V m},
$$

where $S c\left(\mathrm{~F} \mathrm{~g}^{-1}\right)$ is the gravimetric specific capacitance, $\Delta t(\mathrm{~s})$ is the galvanostatic discharge time, $\Delta V(\mathrm{~V})$ is the potential window, $m(\mathrm{~g})$ is the mass of the active material, and $I(\mathrm{~A})$ is the response current. $^{28,29}$

\section{Results and discussion}

Fig. 1a shows the typical crystal phases of $\mathrm{LaFeO}_{3}$ at different calcination temperatures and times, based on the XRD spectra. The obvious diffraction peaks at $2 \theta=22.6^{\circ}, 32.2^{\circ}, 39.7^{\circ}, 46.1^{\circ}$, $57.4^{\circ}, 67.6^{\circ}$ and $76.6^{\circ}$ can be indexed to the (101), (121), (220), (202), (240), (242) and (204) crystal planes, respectively, of orthorhombic $\mathrm{LaFeO}_{3}$ with lattice constants $a=5.567 \AA, b=$ $7.855 \AA$ and $c=5.553 \AA$ (JCPDS no: $37-1493$ ). We find that sample crystallinity increases with increasing calcination temperature for the same calcination time. Simultaneously, by comparing the samples calcined at $700{ }^{\circ} \mathrm{C}$ for 2,3 and $4 \mathrm{~h}$, we find that the calcination time has little effect on the crystallinity of the sample. Notably, there are no additional diffraction peaks in the XRD spectra of any of the samples, indicating that changing the calcination temperature and time does not affect the purity of the sample. Moreover, it shows that the prepared samples are of high purity.

The surface state of the $\mathrm{LaFeO}_{3}$ sample prepared at $700{ }^{\circ} \mathrm{C}$ for $3 \mathrm{~h}$ was further investigated using XPS (Fig. 1b-d). As shown in Fig. 1b, the shape and position of the La3d peak indicate the 

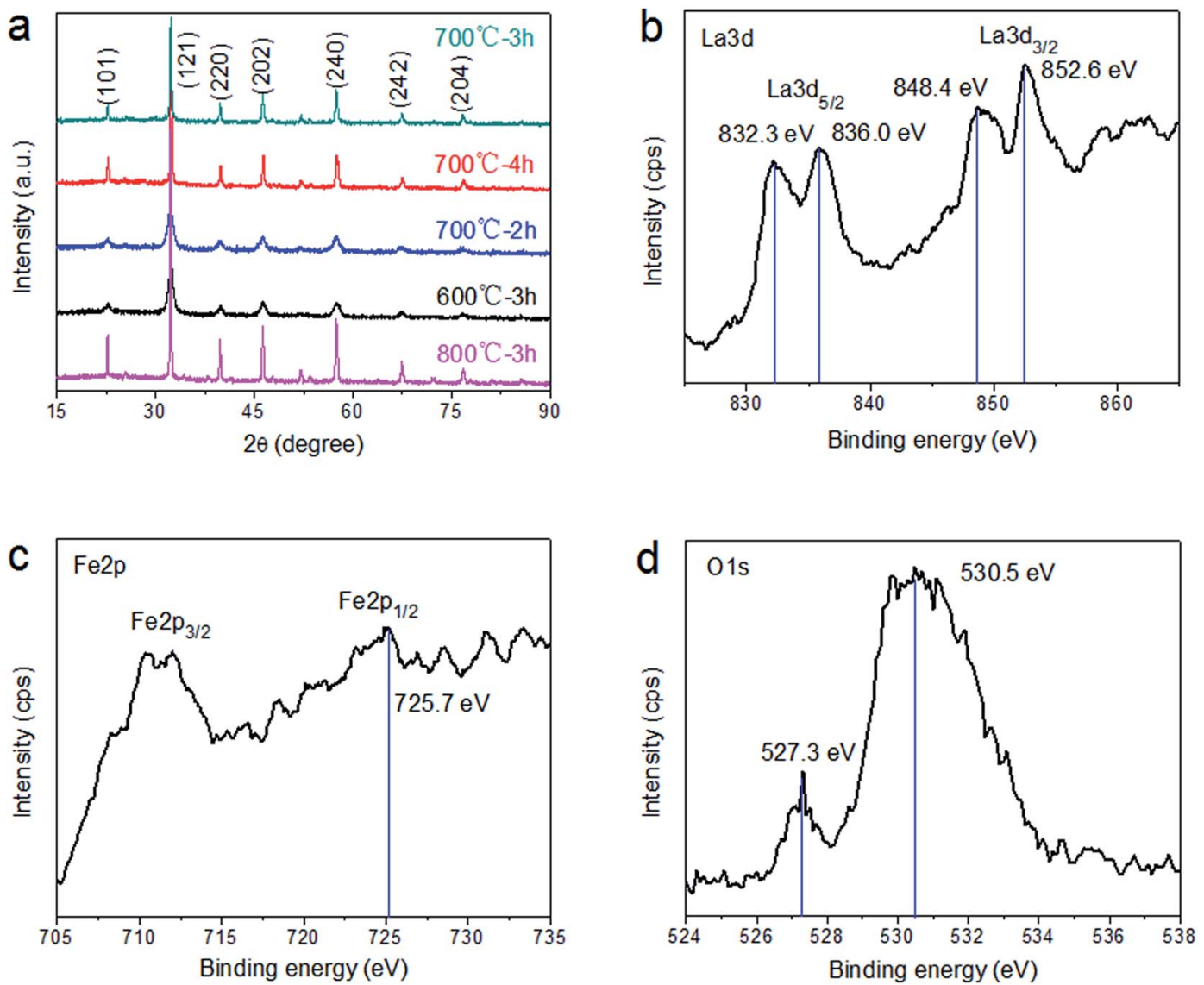

Fig. 1 (a) XRD patterns of $\mathrm{LaFeO}_{3}$ at different calcination temperatures and times. XPS spectra of the (b) La3d, (c) Fe2p and (d) O1s peaks of the $\mathrm{LaFeO}_{3}$ sample prepared at $700{ }^{\circ} \mathrm{C}$ for $3 \mathrm{~h}$.

presence of $\mathrm{La}(\mathrm{III})$ compounds, in agreement with previous literature reports. ${ }^{30}$ In addition, the two peaks located at around 832.3 and $836.0 \mathrm{eV}$ correspond to $\mathrm{La} \mathrm{d}_{5 / 2}$, while the peaks at 848.4 and $852.6 \mathrm{eV}$ correspond to $\mathrm{La}_{3 / 2}$. The Fe2p peaks are presented in Fig. 1c. The peaks at around 712.0 and $725.7 \mathrm{eV}$ correspond to $\mathrm{Fe} 2 \mathrm{p}_{3 / 2}$ and $\mathrm{Fe} 2 \mathrm{p}_{1 / 2}$, respectively, indicating the presence of $\mathrm{Fe}^{3+}$ ions in the $\mathrm{LaFeO}_{3}$ sample. ${ }^{31}$ An obvious peak at around $530.5 \mathrm{eV}$ and a satellite peak at $527.3 \mathrm{eV}$ are observed in the 01s spectrum shown in Fig. 1d. The binding energy of
$530.5 \mathrm{eV}$ is attributed to weakly bound oxygen on the surface (e.g., surface hydroxyl groups and adsorbed oxygen). The satellite peak at $527.3 \mathrm{eV}$ is mainly due to lattice oxygen in $\mathrm{LaFeO}_{3}$. Additionally, the O1s peak asymmetry indicates that the obtained $\mathrm{LaFeO}_{3}$ samples exhibit oxygen vacancies resulting in a slight shift in the main peak.

The morphology and microstructure will have a great effect on the electrochemical performance of the material for practical application in energy storage devices, mainly reflected in the
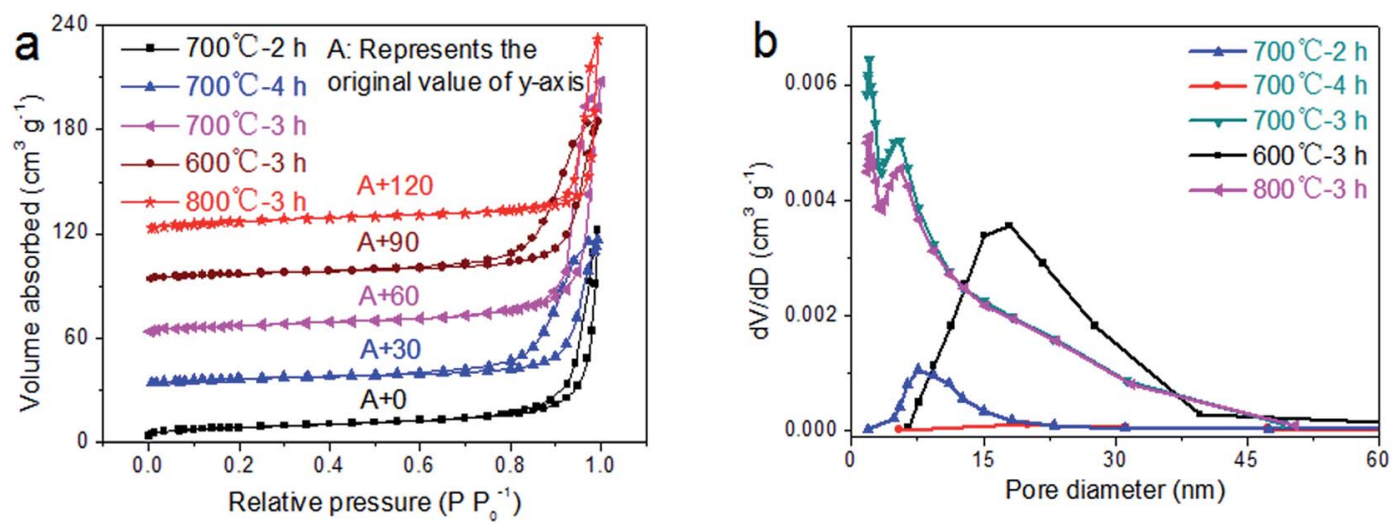

Fig. 2 (a) $\mathrm{N}_{2}$ adsorption-desorption isotherms and (b) pore size distributions of the $\mathrm{LaFeO}_{3}$ samples prepared at different calcination temperatures and times. 
Table 1 Textural parameters of the $\mathrm{LaFeO}_{3}$ samples prepared at different calcination temperatures and times ${ }^{a}$

\begin{tabular}{llcl}
\hline Sample & $S_{\text {BET }}\left(\mathrm{m}^{2} \mathrm{~g}^{-1}\right)$ & $D_{\text {DFT }}(\mathrm{nm})$ & $V\left(\mathrm{~cm}^{3} \mathrm{~g}^{-1}\right)$ \\
\hline $700{ }^{\circ} \mathrm{C}, 2 \mathrm{~h}$ & 40.26 & 7.548 & 0.092 \\
$700{ }^{\circ} \mathrm{C}, 4 \mathrm{~h}$ & 22.37 & 13.312 & 0.068 \\
$700{ }^{\circ} \mathrm{C}, 3 \mathrm{~h}$ & $\mathbf{4 5 . 0 9}$ & 6.797 & $\mathbf{0 . 1 1 1}$ \\
$600{ }^{\circ} \mathrm{C}, 3 \mathrm{~h}$ & 26.62 & 16.855 & 0.044 \\
$800{ }^{\circ} \mathrm{C}, 3 \mathrm{~h}$ & 38.80 & 6.636 & 0.087
\end{tabular}

${ }^{a} S_{\mathrm{BET}}$ represents the BET surface area; $D_{\mathrm{DFT}}$ is the DFT desorption average pore diameter; $V$ stands for the total pore volume.

effective contact area and electron/ion transport resistance. ${ }^{32-34}$ To demonstrate the effects of calcination temperature and time on the specific surface area, pore volume and size of $\mathrm{LaFeO}_{3}$ materials, we characterized the BET surface areas and pore size distributions of the prepared $\mathrm{LaFeO}_{3}$ samples using $\mathrm{N}_{2}$ adsorption-desorption measurements. As shown in Fig. 2a, the typical type-IV isotherm of $\mathrm{LaFeO}_{3}$ with a hysteresis loop at a $P$ $P_{0}{ }^{-1}$ of $0.75-0.9$ indicates the presence of mesoporous structures in the materials. ${ }^{35}$ This result can be further verified from Fig. 2b, which exhibits a large number of smaller mesoporous in $\mathrm{LaFeO}_{3}$ materials. Moreover, we can clearly observe that when the calcination temperature and time are $700{ }^{\circ} \mathrm{C}$ and $3 \mathrm{~h}$, the sample has a greater volume change and small pore diameter of about $6.8 \mathrm{~nm}$, indicating that the sample has a larger specific surface area. The textural parameters of the obtained $\mathrm{LaFeO}_{3}$ samples at different calcination temperatures and times are listed in Table 1. Compared to other samples under different calcination conditions, the sample obtained at $700{ }^{\circ} \mathrm{C}$ and $3 \mathrm{~h}$ possesses the largest specific surface area $\left(45.09 \mathrm{~m}^{2} \mathrm{~g}^{-1}\right)$ and total pore volume $\left(0.111 \mathrm{~cm}^{3} \mathrm{~g}^{-1}\right)$, thereby providing more reaction sites and less ion transfer resistance for electrode materials. Therefore, the experimental data show that the calcination temperature and time have a great influence on the structure of the $\mathrm{LaFeO}_{3}$ material, and the material produced at $700{ }^{\circ} \mathrm{C}$ for $3 \mathrm{~h}$ has the best electrochemical performance.

Fig. 3 presents scanning electron microscopy (SEM) images of $\mathrm{LaFeO}_{3}$ samples prepared at different calcination temperatures and times. As shown in Fig. 3a-c, calcination time has a great influence on the morphology of the material when the calcination temperature is $700{ }^{\circ} \mathrm{C}$. When the calcination time is 2 or $3 \mathrm{~h}$, a large number of tubular $\mathrm{LaFeO}_{3}$ particles are observed. In addition, when the calcination time is $3 \mathrm{~h}$, the quantity of tubular $\mathrm{LaFeO}_{3}$ in the material is higher, and the diameters of the nanotubes are finer (about $25 \mathrm{~nm}$ ). Similarly, by comparing Fig. $3 \mathrm{~b}, \mathrm{~d}$ and e, we find that a large number of tubular $\mathrm{LaFeO}_{3}$ particles are found when the calcination temperature is $800^{\circ} \mathrm{C}$. Nevertheless, a small number of tubular $\mathrm{LaFeO}_{3}$ particles appear at the calcination temperature of
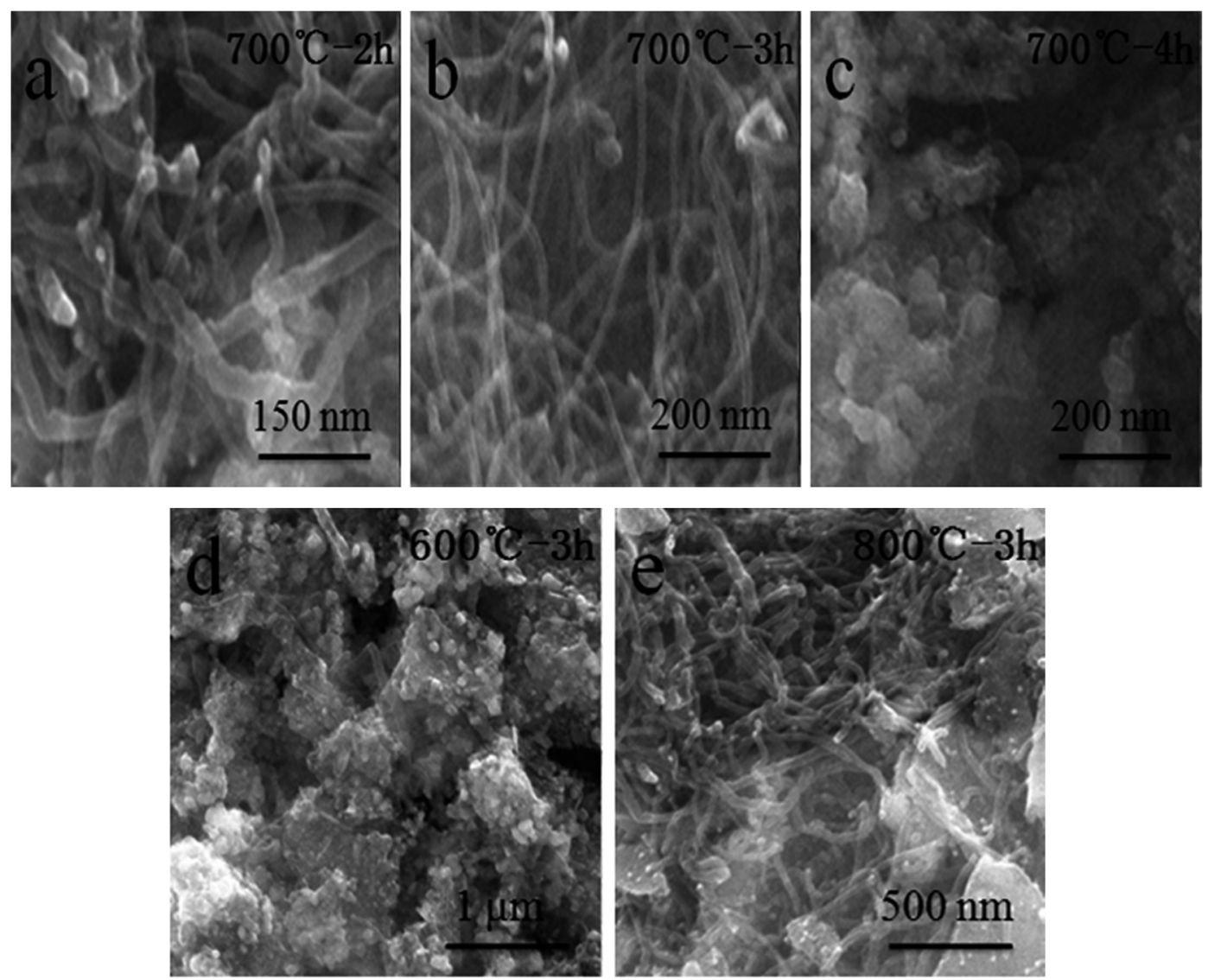

Fig. $3 \mathrm{SEM}$ images of $\mathrm{LaFeO}_{3}$ samples prepared at different calcination temperatures and times: (a) $700{ }^{\circ} \mathrm{C}, 2 \mathrm{~h}$; (b) $700{ }^{\circ} \mathrm{C}, 3 \mathrm{~h}$; (c) $700{ }^{\circ} \mathrm{C}, 4 \mathrm{~h}$; (d) $600^{\circ} \mathrm{C}, 3 \mathrm{~h}$; and (e) $800^{\circ} \mathrm{C}, 3 \mathrm{~h}$. 
$600{ }^{\circ} \mathrm{C}$, and the fracturing of the nanotubes is more serious. The results show that calcination temperature has a large effect on the morphology and nanostructure of $\mathrm{LaFeO}_{3}$. In summary, we find that changing the temperature and time of calcination greatly affects the morphology and structure of the material, which is consistent with the $\mathrm{N}_{2}$ adsorption-desorption measurements. This has important implications for the electrochemical performance of electrode materials, such as the effects on the capacitance of the electrode of the number of sites for the redox reaction and of the surface area for ion adsorption, and the effects of nanostructures on the electron/ion transmission resistance.

The electrochemical performances of the fabricated $\mathrm{LaFeO}_{3}$ electrodes were investigated by CV curves, GCD curves and EIS measurement in $2 \mathrm{M} \mathrm{KOH}$ electrolyte. As illustrated in Fig. 4a, the typical GCD curves at different calcination temperatures and times demonstrate that the specific capacitance for the sample fabricated at $700{ }^{\circ} \mathrm{C}$ for $3 \mathrm{~h}$ is obviously higher than those of other samples, at a current density of $1 \mathrm{~A} \mathrm{~g}^{-1}$. Moreover, the GCD curves for the different calcination conditions are all approximately symmetrical, which indicate ideal capacitive
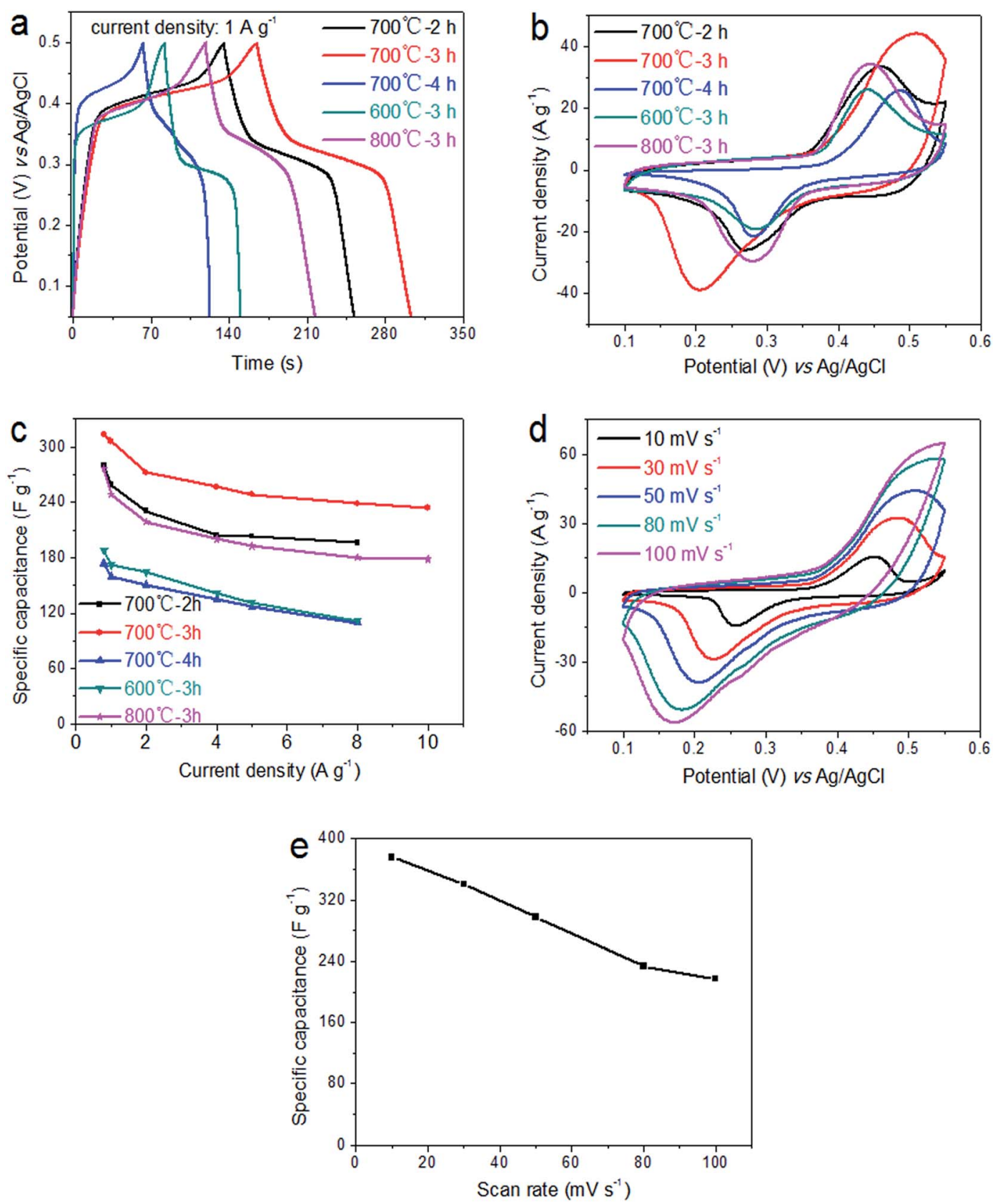

Fig. 4 (a) GCD curves at a current density of $1 \mathrm{~A} \mathrm{~g}^{-1}$ and (b) $\mathrm{CV}$ curves at a scan rate of $50 \mathrm{mV} \mathrm{s}^{-1}$ of the prepared LaFeO 3 electrodes fabricated under different calcination temperatures and times. (c) Specific capacitance as a function of current density for different electrodes. (d) $\mathrm{CV}$ curves and (e) specific capacitances of $\mathrm{LaFeO}_{3}$ electrodes fabricated at $700{ }^{\circ} \mathrm{C}$ for $3 \mathrm{~h}$ in $2 \mathrm{M} \mathrm{KOH}$ aqueous solution at different scan rates. 

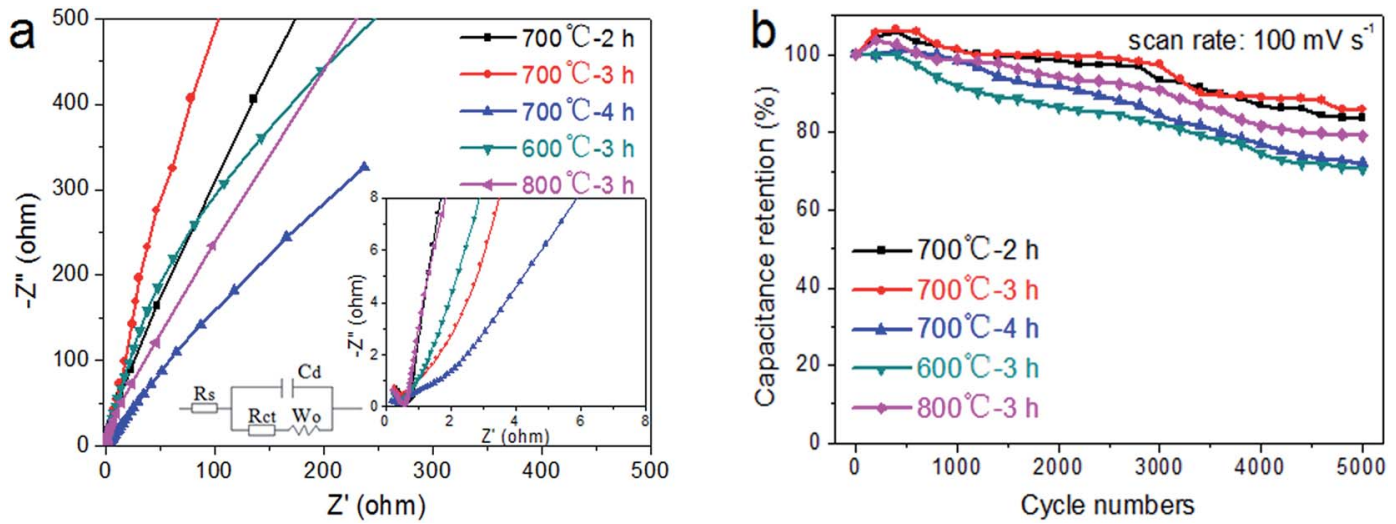

Fig. 5 (a) Nyquist plots of $\mathrm{LaFeO}_{3}$ electrodes prepared at different calcination temperatures and times in the frequency range of $0.01 \mathrm{~Hz}$ to 100 $\mathrm{kHz}$. (b) Comparison of the cycle stabilities at a scan rate of $100 \mathrm{mV} \mathrm{s}^{-1}$ for electrodes prepared at different calcination temperatures and times.

properties and excellent reversible redox reactions. Remarkably, according to the slope of the curve, the charging curve and discharge curve can be divided into three parts. Taking the discharge curve as an example, the straight lines of the potential regions from 0.05 to $0.28 \mathrm{~V}$ and 0.35 to $0.5 \mathrm{~V}$ have large slopes, indicating that the charge storage comes primarily from the double layer produced by the electrostatic desorption of electrolyte ions at the electrolyte/electrode interface. Similarly, the charge storage in the low-slope part of the curve $(0.28-0.35 \mathrm{~V})$ is mainly attributed to the redox reaction between $\mathrm{Fe}^{3+}$ and $\mathrm{Fe}^{2+}$ ions. A comparison of the $\mathrm{CV}$ curves of the electrodes under different calcination conditions is shown in Fig. 4b. All the CV curves have a pair of peaks between 0.1 and $0.55 \mathrm{~V}$, and the area under the curve for the sample fabricated at $700{ }^{\circ} \mathrm{C}$ for $3 \mathrm{~h}$ is significantly larger than for the samples fabricated under other calcination conditions. This indicates that higher specific capacitance values were obtained by using our method (calculated according to the equation $S c=\frac{\int I \mathrm{~d} V}{v m \Delta V}$, where $S c\left(\mathrm{~F} \mathrm{~g}^{-1}\right)$ is the specific capacitance, $\Delta V(\mathrm{~V})$ is the potential windows, $m(\mathrm{~g})$ is the mass of the active material, $v\left(\mathrm{~V} \mathrm{~s}^{-1}\right)$ is the potential scan rate, and $I(\mathrm{~A})$ is the response current $\left.{ }^{36,37}\right)$. The results are in good agreement with the GCD results. Fig. $4 \mathrm{c}$ shows the specific capacitances of $\mathrm{LaFeO}_{3}$ electrodes at various current densities evaluated from the GCD curves. We can clearly see that the specific capacitances of the electrode formed at $700{ }^{\circ} \mathrm{C}$ for $3 \mathrm{~h}$ are much higher than those of electrodes formed under other conditions at different current densities. Furthermore, the specific capacitance of the $\mathrm{LaFeO}_{3}$ electrode formed at $700{ }^{\circ} \mathrm{C}$ for $3 \mathrm{~h}$ still retains about $74.71 \%$ at $0.8 \mathrm{~A} \mathrm{~g}^{-1}\left(313.21 \mathrm{~F} \mathrm{~g}^{-1}\right)$ and $10 \mathrm{~A} \mathrm{~g}^{-1}\left(234 \mathrm{~F} \mathrm{~g}^{-1}\right)$, indicating an excellent rate capability. The $\mathrm{CV}$ curves of the electrode under the conditions of optimum electrochemical performance are shown in Fig. 4d. All the curves have a pair of redox peaks and maintain similar shapes as scan rate increases, indicating that the generation of capacitance is mainly due to the redox reaction. The shift in peak position towards both ends is caused by the internal diffusion resistance in the electrode. ${ }^{38}$ The specific capacitances at different scan rates for the electrode formed at $700^{\circ} \mathrm{C}$ for $3 \mathrm{~h}$ are shown in Fig. 4e. We find that the electrode possesses a high specific capacitance of $375.76 \mathrm{~F} \mathrm{~g}^{-1}$ at a scan rate of $10 \mathrm{mV} \mathrm{s}^{-1}$. Even when the scan rate is increased to $100 \mathrm{mV} \mathrm{s}^{-1}$, the electrode retains a specific capacitance of $217.21 \mathrm{~F} \mathrm{~g}^{-1}$, indicating good electrochemical performance.

EIS can provide insight into the structure and distribution of the active material attached to the current collector and how they affect the electrochemical performance of the device. ${ }^{39}$ In Fig. $5 \mathrm{a}$, the EIS spectra of $\mathrm{LaFeO}_{3}$ electrodes formed at different calcination temperatures and times are compared from $100 \mathrm{kHz}$ to $0.01 \mathrm{~Hz}$ at an amplitude of $5 \mathrm{mV}$. The Nyquist plots, which represent the resistance behavior following frequency changes, are composed of two parts: an irregular semicircle corresponding to the Faraday reaction in the high-frequency region, and a straight line in the low-frequency region. ${ }^{26}$ For the electrode fabricated at $700{ }^{\circ} \mathrm{C}$ for $3 \mathrm{~h}$, the straight line in the lowfrequency region is more parallel to the imaginary axis than for the other electrodes, indicating a lower Warburg impedance $\left(W_{0}\right)$ and charge transfer resistance $\left(R_{\mathrm{ct}}\right)$ of ion diffusion. ${ }^{40}$ In addition, these lines with slopes of $40-80^{\circ}$ are consistent with the characteristics of pseudocapacitance behavior. The electrochemical cyclic stability of the electrode is also an important parameter in the practical application of the supercapacitor. As illustrated in Fig. 5b, the specific capacitance of the $\mathrm{LaFeO}_{3}$ electrode fabricated at $700{ }^{\circ} \mathrm{C}$ for $3 \mathrm{~h}$ is maintained at about $86.1 \%$ of the initial capacitance after 5000 cycles at a scan rate of $100 \mathrm{mV} \mathrm{s}^{-1}$, which is higher than for the other electrodes [about $83.69 \%\left(700{ }^{\circ} \mathrm{C}, 2 \mathrm{~h}\right), 72.1 \%\left(700{ }^{\circ} \mathrm{C}, 4 \mathrm{~h}\right), 70.55 \%\left(600{ }^{\circ} \mathrm{C}, 3 \mathrm{~h}\right)$, and $79.1 \%\left(800{ }^{\circ} \mathrm{C}, 3 \mathrm{~h}\right)$. This again demonstrates that a better cycle stability is obtained at $700^{\circ} \mathrm{C}$ and $3 \mathrm{~h}$, and the calcination temperature and time have great effects on the electrochemical properties of the electrode materials, which may be mainly attributed to the changes in the morphology and microstructure of the material.

\section{Conclusions}

In summary, novel perovskite-type oxide $\mathrm{LaFeO}_{3}$ nanotubes were fabricated at different calcination temperatures and times using a simple sol-gel method and further calcination treatment. The results show that the calcination temperature and 
time have large effects on the morphology, structure and electrochemical performance. The $\mathrm{LaFeO}_{3}$ nanotube electrode fabricated at $700{ }^{\circ} \mathrm{C}$ for $3 \mathrm{~h}$ exhibits the best electrochemical performance, with the best specific capacitance of $313.21 \mathrm{~F} \mathrm{~g}^{-1}$ at a current density of $0.8 \mathrm{~A} \mathrm{~g}^{-1}$ and excellent cyclic stability with $86.1 \%$ capacitance retention after 5000 cycles at a scan rate of $100 \mathrm{mV} \mathrm{s}^{-1}$. These excellent electrochemical properties suggest that the novel $\mathrm{LaFeO}_{3}$ nanotubes obtained here are a promising electrode material worthy of further investigation for practical applications in energy storage devices.

\section{Acknowledgements}

The authors are grateful for support from the Henan Provincial Department of Education (No. 17A140013), the National Natural Science Foundation of China (No. 51472102, 21503194) and the Graduates' Scientific Research Foundation of Zhengzhou University of Light Industry.

\section{References}

1 Y. Y. Wang, Y. Lei, J. Li, L. Gu, H. Y. Yuan and D. Xiao, ACS Appl. Mater. Interfaces, 2014, 6, 6739-6747.

2 L. W. Hu, Z. J. Yu, Z. Q. Hu, Y. Song, F. Zhang, H. M. Zhu and S. Q. Jiao, Electrochim. Acta, 2015, 174, 273-281.

3 Z. J. Li, W. Y. Zhang, Y. L. Su, H. Y. Wang and B. C. Yang, Appl. Surf. Sci., 2016, 383, 268-275.

4 D. S. Yu, K. L. Goh, H. Wang, L. Wei, W. C. Jiang, Q. Zhang, L. M. Dai and Y. Chen, Nat. Nanotechnol., 2014, 9, 555-562.

5 M. F. Elkady and R. B. Kaner, Nat. Commun., 2013, 4, 1475.

6 S. L. Chen, F. Liu, Q. J. Xiang, X. H. Feng and G. H. Qiu, Electrochim. Acta, 2013, 106, 360-371.

7 T. Tevi and A. Takshi, J. Power Sources, 2015, 273, 857-862.

8 Y. P. Zhai, Y. Q. Dou, D. Y. Zhao, P. F. Fulvio, R. T. Mayes and S. Dai, Adv. Mater., 2011, 22, 4828-4850.

9 T. Chen, H. S. Peng, M. Durstock and L. M. Dai, Sci. Rep., 2014, 4, 204-208.

10 Y. Gao, D. L. Wu, T. Wang, D. Z. Jia, W. Xia, Y. Lv, Y. L. Cao, Y. Y. Tan and P. G. Liu, Electrochim. Acta, 2016, 191, 275-283.

11 Q. Y. Liao, N. Li, S. X. Jin, G. W. Yang and C. X. Wang, ACS Nano, 2015, 9, 5310-5317.

12 Y. Zhao, L. F. Hu, S. Y. Zhao and L. M. Wu, Adv. Funct. Mater., 2016, 26, 4085-4093.

13 S. D. Min, C. J. Zhao, G. R. Chen, Z. M. Zhang and X. Z. Qian, Electrochim. Acta, 2014, 135, 336-344.

14 Z. N. Yu, B. Duong, D. Abbitt and J. Thomas, Adv. Mater., 2013, 25, 3302-3306.

15 Y. Haldorai, W. Voit and J. J. Shim, Electrochim. Acta, 2014, 120, 65-72.

16 M. Guo, J. Balamurugan, T. D. Thanh, N. H. Kim and J. H. Lee, J. Mater. Chem. A, 2016, 4(44), 17560-17571.

17 H. C. Chen, J. J. Jiang, L. Zhang, H. Z. Wan, T. Qi and D. D. Xia, Nanoscale, 2013, 5, 8879-8883.
18 Z. Y. Lu, Q. Yang, W. Zhu, Z. Chang, J. F. Liu, X. M. Sun, D. G. Evans and X. Duan, Nano Res., 2012, 5, 369-378.

19 H. Y. Zhang, Y. P. Ye, Z. H. Li, Y. M. Chen, P. Deng and Y. Y. Li, J. Mater. Sci., 2016, 51, 2877-2885, DOI: 10.1007/ s10853-015-9596-6.

20 J. T. Mefford, W. G. Hardin, S. Dai, K. P. Johnston and K. J. Stevenson, Nat. Mater., 2014, 13, 726-732.

21 P. C. Du, X. W. Hu, C. Yi, H. C. Liu, P. Liu, H. L. Zhang and X. Gong, Adv. Funct. Mater., 2015, 25, 2420-2427.

22 Y. Liu, J. Dinh, M. O Tade and Z. P Shao, ACS Appl. Mater. Interfaces, 2016, 8(36), 23774-23783.

23 L. Zhu, Y. Liu, C. Su, W. Zhou, M. L. Liu and Z. P. Shao, Angew. Chem., 2016, 55(33), 9576-9579.

24 C. O. Soares, R. A. Silva, M. D. Carvalho, M. E. Melo Jorge, A. Gomes, C. M. Rangel and M. I. da Silva Pereira, Electrochim. Acta, 2013, 89(1), 106-113.

25 Z. Z. Du, P. Yang, L. Wang, Y. H. Lu, J. B. Goodenough, J. Zhang and D. W. Zhang, J. Power Sources, 2014, 265(11), 91-96.

26 Y. Cao, B. P. Lin, Y. Sun, H. Yang and X. Q. Zhang, Electrochim. Acta, 2015, 174, 41-50.

27 T. Esaka, H. Sakaguchi and S. Kobayashi, Solid State Ionics, 2004, 166(3), 351-357.

28 F. H. Li, X. Y. Xu, F. L. Xia, L. Zhang, T. Wu, S. L. Li and W. Wang, Sci. Adv. Mater., 2015, 7(9), 269-277, DOI: 10.1166/sam.2015.2017.

29 M. Hakamada, T. Abe and M. Mabuchi, J. Power Sources, 2016, 325, 670-674.

30 X. P. Dai, J. Cheng, Z. Z. Li, M. Z. Liu, Y. D. Ma and X. Zhang, Chem. Eng. Sci., 2016, 153, 236-245.

31 K. K. Bhargav, A. Maity, S. Ram and S. B. Majumder, Sens. Actuators, B, 2014, 195(5), 303-312.

32 W. Tian, X. Wang, C. Y. Zhi, T. Y. Zhai, D. Q. Liu, C. Zhang, D. Golberg and Y. Bando, Nano Energy, 2013, 2, 754-763.

33 X. W. Hu, S. Liu, C. H. Li, J. H. Huang, J. X. Lv, P. Xu, J. Liu and X. Z. You, Nanoscale, 2016, 8, 11797-11802.

34 G. Lota, K. Fic and E. Frackowiak, Energy Environ. Sci., 2011, 4, 1592-1605.

35 S. I. Kim, P. Thiyagarajan and J. H. Jang, Nanoscale, 2014, 6, 11646-11652.

36 G. L. Sun, H. Y. Xie, J. B. Ran, L. Y. Ma, X. Y. Shen, J. M. Hu and H. Tong, J. Mater. Chem. A, 2016, 4, 16576-16587.

37 L. Zhu, Y. Liu, C. Su, W. Zhou, M. L. Liu and Z. P. Shao, Angew. Chem., Int. Ed., 2016, 55, 9576-9579.

38 J. Yan, Z. J. Fan, W. Sun, G. Q. Ning, T. Wei, Q. Zhang, R. F. Zhang, L. J. Zhi and F. Wei, Adv. Funct. Mater., 2012, 22, 2632-2641.

39 S. Y. Wang and R. A. W. Dryfe, J. Mater. Chem. A, 2013, 1, 5279-5283.

40 C. X. Yang, Q. M. Gao, W. Q. Tian, Y. L. Tan, T. Zhang, K. Yang and L. H. Zhu, J. Mater. Chem. A, 2014, 2, 1997519982. 